Mendes I.A.C. e Colaboradora - As Fontes do Conhecimento e as Tendências Subjacentes nos Artigos Publicados na Revista Brasileira de Enfermagem, de 1970 a 1981 Rev. Bras. Enf.; RS.36: 154 - 163, 1983 .

4. CONSELHO NACIONAL DE DESENVOLVIMENO CIENTÍFICO E TECNOLÓGICO - CNPq. Manual de Procedimentos do Candidato - Tabela 4 - Sub-Áreas do Conhecimento, 1982.

5. COORDENAÇÃO DE APERFEIÇOAMENTO DE PESSOAL DE NÍVEL SUPERIOR - CAPES. Tabela de Áreas e Sub-Áreas do Conhecimento, 1981.

6. FUNDAÇÃO DE AMPARO À PESQUISA DO ESTADO DE SÃO PAULO - FAPESP. Classificação das grandes áreas, áreas e sub-áreas do conhecimento, 1982.

7. MENDES, I. A. C. \& TREVIZAN, M. A. - Acerca da utilização do método científico nas pesquisas de enfermagem. Rev. Bras. Enf., 36 (1): 13-19, 1983.

8. OGUISSO, T. \& SCHMIDT, M. J. - Problemas assistenciais de enfermagem nos hospitais e clínicas particulares. Rev. Bras. Enf., 29 (1): 24-37, 1976.

9. POLIT, D. F. \& HUNGLER, B. P. - Nursing Research: Principles and Methods. Philadelphia, J. B. Lippincott Co., 1978.

10. SÁ, E. S. - Participação dos pesquisadores de microbiologia, imunologia e parasitologia (MIP) na literatura científica nacional. Ci. Inf., Rio de Janeiro, 5 (1/2): 43-69, 1976.

11. SALVADOR, A. D. - Métodos e técnicas de pesquisa bibliográfica, elaboração e relatório de estudos científicos. 10a ed., Porto Alegre, 1982.

12. TREVIZAN, M. A. \& MENDES, I. A. C. - Sobre a expansão do conhecimento segundo Popper. Rev. Gaúcha de Enfemagem, 4 (2): 215-221, julho de 1983.

\title{
A ERVA-DOCE E SEU EFEITO GALACTÓGENO (UM ESTUDO EXPERIMENTAL)
}

* Sílvia Nóbrega

Neiva Francenely

ReBEn/05

Nóbrega S. e Colaboradora - A Erva-Doce e seu Efeito Galactógeno (Um Estudo Experimental). Rev. Bras. Enf.; RS, 36: 163 - 177, 1983

\begin{abstract}
RESUMO
O objetivo do presente trabalho é a comprovação da potencialidade da Erva-doce como estimulante galactógeno.

Aplicou-se questionário a gestantes do último trimestre gestacional, inscritas no prénatal da maternidaded do município de Aquiraz, no sentido de selecionar uma amostra intencional, com história comum de desmame precoce por insuficiência de leite.

Com base nos resultados obtidos no referido trabalho, pretende-se recomendar a utilização da Erva-doce, como tecnologia apropriada, o que seria mais uma estratégia para a melhoria da saúde da díade mãe-filho.
\end{abstract}

\footnotetext{
* Enfermeiras de Saúde Pública lotadas na Secretaria de Saúde do Estado do Ceará, Divisão de Treinamento.
} 
Nóbrega S. e Colaboradora - A Erva-Doce e seu Efeito Galactógeno (Um Estudo Experimental).

Rev. Bras. Enf.; RS.36: 163 - 177, 1983.

\section{INTRODUÇÃO}

\subsection{Revisão Bibliográfica}

Desde o início da gestação um complexo hormonal desencadeia uma série de ações para produção do leite. As glândulas mamárias crescem a partir da estimulação dos hormônios estrógenos e progesterona. Os hormônios esteróides sexuais mantêm-se em taxas elevadas inibindo a liberação da prolactina LH. Tão logo o bebê nasça, essas taxas se reduzem, a prolactina se eleva, atua sobre os alvéolos mamários e surge o leite ${ }^{(2,7,11)}$. Por outro lado, a manutenção da secreção láctea dependerá de um mecanismo reflexo a partir da sucção da mama ${ }^{(6,11)}$. No entanto há autores que referem que a sucção, por si só, não é condição necessária para manutenção dessa função(2). Segundo HARNACK(5), "o esvaziamento regular e completo das mamas é o único estímulo eficaz para a secreção do leite".

A curva de declínio da amamentação tem sido um dos mais graves problemas de Saúde Pública $(9,11,14)$. O significado biológico, social, psicológico e econômico, que a díade mãe-filho representa, tem requerido uma atenção especial para a saúde de ambos, uma vez que os agravos em qualquer um deles afetarão o outro.

O desmame precoce, perigo de risco em potencial para a criança, tem sido um dos responsáveis pelo baixo peso, concorrendo para infecções graves. Causas várias têm levado ao desmame precoce. Estas tanto podem ser advindas de fatores relativos à mãe, interferindo na criança e vice-versa, prejudicando o equilíbrio bio-psico-social da díade mãe-filho $(6,9,14)$.

O não esvaziamento completo do peito pelo bebê e/ou desmamadeira, segundo HARNACK $^{(5)} \mathrm{BENSON}^{(2)}$, pode levar a produção do leite ao declínio.

A maneira como a mãe leva o bebê ao peito e a satisfação que esta sente em amamentar são fatores que contribuem para boa amamentação( $(2,5)$.

Talvez se possa inferir do acima exposto que as causas e efeitos alegados no desmame precoce estão tão interligados entre si, que as razões para se desejar ou não amamentar não são sentidas ou percebidas pela mãe, alegando esta a rejeição ao peito e pouco leite(3).

Além dos fatores acima citados, práticas puerperais em maternidades convencionais

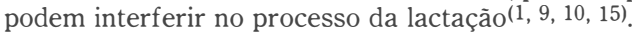

"-Início tardio da amamentação;

- recém-nascido sedado (excesso de anestesia na mãe);

- alimentação complementar em mamadeiras;

- não alojamento conjunto;

- incentivo à utilização de alimentos infantis industrializados;

- mãe desinformada e confusa;

- mãe cansada sem comer e beber;

- episiotomia rotineira (dor);

- restrição de visitas;

- insensibilidade da equipe de saúde". $9,12)$.

As dificuldades acima referidas podem levar à agalactia ou hipogalactia precoce ${ }^{(3,5}$,

Em pesquisa realizada em 1976, o pediatra José Martins Filho diz que: "somente uma mulher em terceiro grau de desnutrição grave, não teria condições de amamentar seu filho"'(3).

A Dra ${ }^{a}$ Merril Middlemore reafirma e completa: "somente mães exauridas e subnutridas tendem a ter problemas de ordem física para dificultar o aleitamento"(3).

Em recente pesquisa de campo realizada no município de Aquiraz sobre ervas utilizadas no cuidado caseiro da saúde, foram identificadas com base científica que o gergelim, a erva-doce e o algodoeiro têm efeito galactógeno $(4,8)$.

Diante do reconhecimento dos fatores acima citados e da importância da prática da amamientação conhecida por toda literatura que aborda o assunto, surgiu a necessidade de se fazer um estudo na tentativa de comprovação de efeitos galactógenos atribuídos à erva-doce, em mães com história de desmame precoce por insuficiência de secreção láctea no município de Aquiraz.

1.2.Dados sobre a maternidade de Aquiraz

- Localiza-se na Sede do município.

- É assistida pelo Programa de Atenção Primária em Saúde (PAPS) mantido pela Fundação Kellogg. 
Nóbrega S. e Colaboradora - A Erva-Doce e seu Efeito Galactógeno (Um Estudo Experimental). Rev. Bras. Enf.; RS.36: 163 - 177, 1983.

- Funciona com 9 parteiras treinadas, pertencentes à própria comunidade, 1 enfermeira* e 1 médico**.

- Nela, as gestantes escolhem o tipo de parto ao qual querem se submeter: posição deitada, sentada ou de cócoras.

- O ambiente é tranqüilo.

- O sistema de alojamento mãe-filho é conjunto.

- A mãe raramente é episiotomizada***

- A alimentação só é oferecida para a mãe.

- A amamentação é iniciada nas primeiras horas do puerpério.

1.3. Base científica da Erva-doce

Nome popular - Erva-doce

Nome científico - Pipinella anisum

Princípio Ativo - óleo essencial formado quase exclusivamente de anetol.

Fórmula Química do Anetol - $\mathrm{C} \mathrm{H}_{4}>\mathrm{OCH} 3$

Segundo o Dr. Pinho****, através de estudos realizados em autores como Pio Marffere e Pulsem, deve-se ao anectol o efeito galactógeno atribuído ao erva-doce.

\section{METODOLOGIA}

Este estudo foi realizado no município de Aquiraz, a partir da maternidade local.

\section{População:}

Quatorze (14) puérperas do município de Aquiraz, com pré-natal e parto realizado na maternidade local.

\footnotetext{
Amostra:

1. fase: selecionada de forma intencional a partir de formulários, Anexo I, aplicados durante 30 dias a gestantes do último trimestre.

$2^{\mathrm{a}}$ fase: inclui 5 puérperas, selecionadas quando gestantes do último trimestre.

Critérios para seleção da amostra:

- história comum de desmame precoce ${ }^{* * * * *}$ por insuficiência de leite no puerpério anterior

- proeminência de mamilo;

- ausência de contra-indicação para amamentação decorrente de enfermidades em si própria elou na criança;

- alimentação a qual já estão habituadas com a introdução do chá de erva-doce durante a realização da pesquisa.
}

* supervisiona semanalmente a maternidade.

** consulta semanalmente grupo materno-infantil.

${ }^{* * *}$ nenhuma gestante do grupo amostral foi episiotomizada.

**** Dr. Felizardo de Pinho Pessoa Filho, químico-farmacêutico, Diretor do Laboratório de Análise Clínica do DNOCS-CE, 40 anos de estudos e experiências com ervas.

***** Desmame precoce considerado neste trabalho é o tempo de desmame igual ou inferior a 45 dias. 
Nóbrega S. e Colaboradora - A Erva-Doce e seu Efeito Galactógeno (Um Estudo Experimental).

Rev. Bras. Enf.; RS.36: 163 - 177, 1983.

A adesão espontânea quanto à participação na pesquisa foi assegurada mediante entrevista a cada gestante no próprio domicílio ou na próxima consulta de pré-natal na maternidade (vê Anexo III).

Hipótese:

- 250ml (1 copo) de chá de erva-doce, 4 vezes ao dia, a partir das primeiras horas do puerpério, com a estimulação da glândula mamária, aumenta a secreção láctea.

Cálculo para medir a unidade de tempo para exposição da variável: $\mathrm{x}+5=\mathrm{y}$

$\mathrm{x}=$ número de dias em que a criança (da gestação anterior) foi desmamada.

5 = constante selecionada após a coleta dos primeiros dados do instrumento (vê Anexo

I). Menor número que adicionado ao número de dias em que houve o desmame no puerpério anterior somasse 10 dias. Época recomendada pelo Dr. Pinho * para a coleta dos dados do experimento com maior segurança.

$\mathrm{y}=$ número de dias necessários para exposição da variável.

Variáveis:

- Uso do chá de erva-doce na forma recomendada:

modo de preparar (vê Anexo IV).

posologia

unidade de tempo

- Estimulação da glândula mamária pelo lactente, sempre que desejar.

Procedimentos utilizados quando na experimentação da variável, Anexo V.

Provas significativas da variável:

- A utilização adequada do chá e o ato de sugar com freqüência aumentarão a quantidade de secreção láctea.

- Não haverá associação com outros tipos de ervas ou qualquer outro cuidado caseiro ao qual se atribua popularmente e/ou com base científica efeito galactógeno.

- Não haverá associação com terapêutica farmacológica de qualquer espécie.

Procedimentos e instrumentos:

- Entrevista - com a parteira da maternidade local para verificar a aceitabilitade da mesma quanto à aplicação dos formulários junto às gestantes, dentre as quais foi selecionada posteriormente à amostra.

- Instrumentos para seleção da amostra, Anexo I.

N. 1 - Formulário para seleção da amostra aplicado pela parteira.

Os procedimentos relativos ao pré-teste e treinamento para aplicação do instrumento N. 1 encontram-se no Anexo II.

- Instrumento para coleta dos resultados, Anexo VI.

- № 2 - Formulários para coleta de dados aplicados pelas autoras à amostra selecionada, quando a mesma estiver no puerpério.

Este instrumento não pôde ser previamente testado, uma vez que os dados coletados estavam diretamente ligados ao experimento e o formulário foi aplicado logo após a exposição da variável. 
Nóbrega S. e Colaboradora - A Erva-Doce e seu Efeito Galactógeno (Um Estudo Experimental).

Rev. Bras. Enf.; RS.36: 163 - 177, 1983.

\section{RESULTADOS E DISCUSSÕES}

As Tabelas de 1 a 9 (Anexo VII) apresentam dados referentes aos critérios estabelecidos para a seleção da amostra.

Nas Tabelas 1, 2, 3, 5 (Anexo VII), observa-se que a gravidez feliz, parto normal, experiência boa e o incentivo do companheiro quanto à amamentação parece não terem sido condições suficientes que levassem as mães desse grupo amostral a evitar o desmame precoce no puerpério anterior (Fig. 1).

Os resultados expostos nas Tabelas 6, 7, 9 (Anexo VII) e o item III do instrumento Anexo V, mostram que não há contra indicações para amamentação por parte da mãe e criança.

No que concerne aos dados apresentados nas Tabelas 12, 13, Fig. 1 e Quadro I, verifica-se que o grupo amostral, na sua maioria, $4(80 \%)$, atingiu a meta com relação ao período da amamentação proposto neste trabalho.

No entanto, não se pode dizer que o chá de erva-doce mais o estímulo da glândula mamária tenham sido os únicos fatores que levaram ao alcance do objetivo proposto.

Desejo de amamentar, Tabela 4 (Anexo VII), criança levada ao peito antes da secção do coto, Tabela 10 (Anexo VII), percepção quanto ao ato de amamentação, Tabela 8 (Anexo VII), participação num grupo de pesquisa *, perspectiva de uma visita domiciliar são fatores emocionais que devem ser levados em conta, ao se pretender interpretar os resultados contidos na Fig. 1 e Quadro I.

A o interpretar as possíveis associações destes fatores emocionais com o processo de lactação, deve-se atentar para a possibilidade de serem apenas aparentes. Ou podem existir fatores condicionantes dessa relação que muito ou pouco tenham a ver com este processo.

Ainda com relação aos dados da Fig. 1, a unidade amostral $\mathrm{P}_{2}$, não atingiu a meta (vê Quadro I). Observou-se "in loco" que tal fato ocorreu devido às influências externas ${ }^{* *}$ que a puerpéra sofreu, Quadro II, $\mathrm{D}_{2}$.

Tabela 12 - Comportamento da criança percebido pela mãe após cada mamada. Aquiraz-CE 1982.

Comportamento

após a mamada

Número de crianças

Dorme

04

Chora

01

TOTAL

05

Fonte: Formulário aplicado pelas autoras.

* mesmo sem se conhecerem, sabiam da existência de outras.

** irmãs, vizinhas. 
Nóbrega S. e Colaboradora - A Erva-Doce e seu Efeito Galactógeno (Um Estudo Experimental). Rev. Bras. Enf.; RS.36: $163-177,1983$.

TABELA 13 - Quantidade da secreção láctea/utilização do experimento pelo grupo amostral, tomando como base o puerpério anterior. Aquiraz - Ce, 1982.

\begin{tabular}{lc}
\hline Secreção láctea & Grupo amostral \\
\hline Aumentou & 04 \\
Não aumentou & 01 \\
Diminuiu & - \\
\hline TOTAL & 05 \\
\hline
\end{tabular}

Fonte: Formulário aplicado pelas autoras.

Figura 1 - Período de amamentaçáo por unidade amostral nos puerpérios anterior e atual. Aquiraz. CE., 1982.

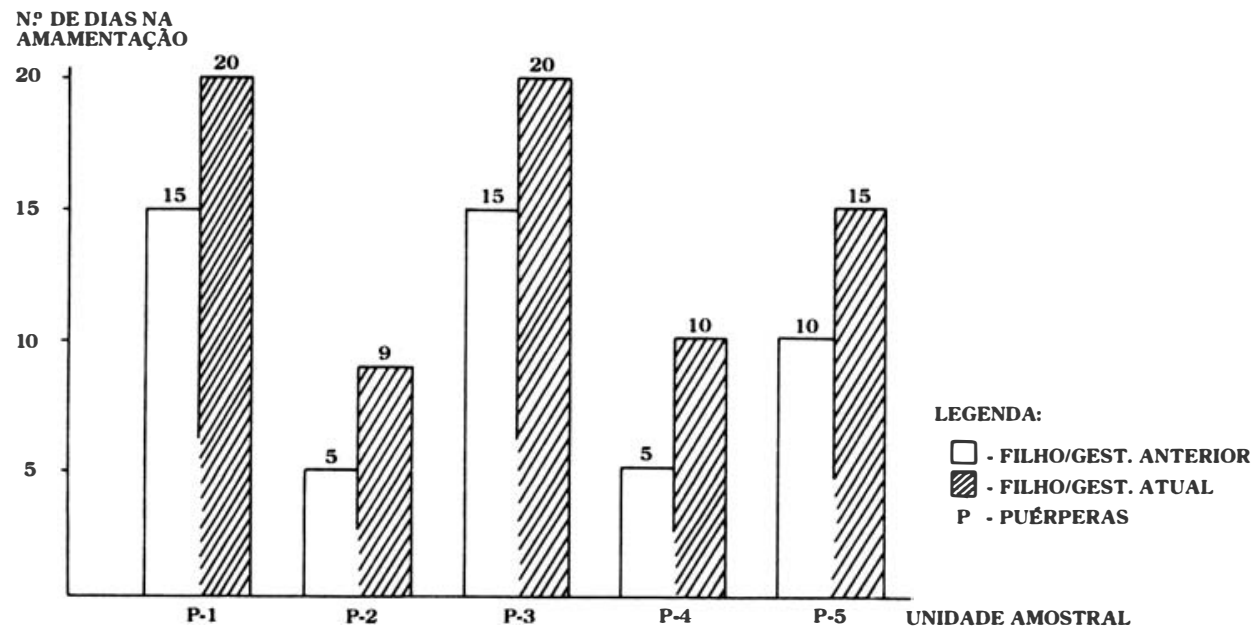


Nóbrega S. e Colaboradora - A Erva-Doce e seu Efeito Galactógeno (Um Estudo Experimental). Rev. Bras. Enf.; RS.36: 163 - 177, 1983.

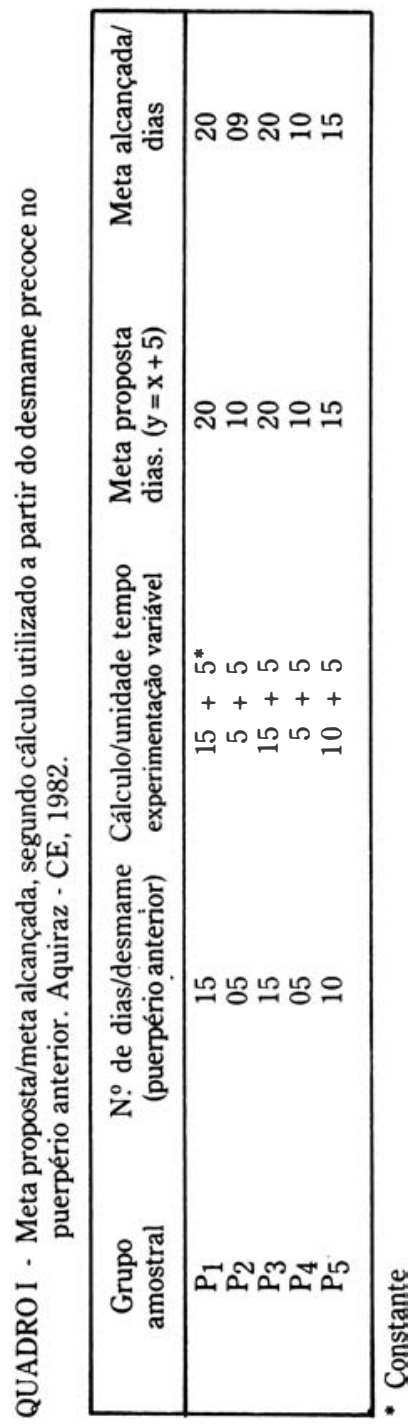

Com referência ao QUADRO I, pode-se calcular o ponto máximo e o ponto mínimo para o número de dias de amamentação da amostra no puerpério anterior. Segundo cálculos estatísticos o menor e o maior número de dias para a amamentação correspondem respectivamente 2,5 dias e 17,5 dias. A possibilidade de acerto com relação a estes dados é de $99,7 \%$.

Com relação ao grupo experimental o ponto máxima e mínimo não pôde ser determinado visto que o desvio padrão foi igual a zero. Seria necessário um maior número de experiências, maior número de dados, etc., para se conseguir dados estatísticos com maior precisão.

As unidades amostrais $\mathrm{P}_{1}$ e $\mathrm{P}_{3}$ amamentaram 20 dias. Não se pode dizer que tenham ultrapassado a média de dias do experimento tomando-se como base o número de dias que as mesmas desmamaram. 
Nóbrega S. e Colaboradora - A Erva-Doce e seu Efeito Galactógeno (Um Estudo Experimental).

Rev. Bras. Enf.; RS.36: 163 - 177, 1983.

Sem a interferência do chá o grupo amostral apresentou uma média de 10 dias (base de dias de desmame no puerpério anterior). No experimento a média de dias no grupo amostral é 15.

Se a média de controle é 10 dias e a média do experimento é 15 dias, verifica-se que a utilização do chá aumenta a probabilidade para a amamentação.

QUADRU II - Depoimentos do grupo amostral sobre as causas do desmame precoce no puerpério anterior e resultados quanto à utilização do experimento. Aquiraz - CE, 1982.

\begin{tabular}{|ll|}
\hline $\mathrm{D}$ *Desmame precoce/puerpério anterior & Utilização do experimento/puérperio atual \\
\hline 1 - o leite estava pouco & - aumentou, acho até mais forte \\
$2-$ a criảnça não fica satisfeita e chora & - as pessoas acham que eu não aguento \\
& sustentar a menina só no peito \\
$3-$ o leite estava secando & - o leite aumentou, acho até que ficou mais \\
& forte \\
$4-$ o leite foi pouco & - aumentou, tem pra mim que foi o chá, eu \\
& tive 3 meninos e nunca tive leite como agora \\
$5-$ o leite era pouco & - aumentou sim, deve ter sido o chá, antes \\
& eu não amamentava \\
\hline
\end{tabular}

* Depoimentos.

Obs.: transcritos na íntegra.

\section{CONCLUSÕES E SUGESTÕES}

De acordo com os dados obtidos sobre a erva-doce e seu efeito galactógeno em 5 puérperas que realizaram pré-natal e parto na maternidade do município de Aquiraz, conclui-se que:

- em $80 \%$ do grupo amostral a secreção láctea aumentou;

- ao aumento da secreção láctea no grupo amostral, não se pôde atribuir somente a utilização da erva-doce e estímulo da glândula mamária;

- outras causas não detectadas no Instrumento 1, item II, Anexo I no grupo amostral, conduziram ao desmame precoce no puerpério anterior.

Considerando que o aleitamento materno é um recurso natural de valor inestimável sobretudo nos países em desenvolvimento, sugere-se que:

- intensifiquem-se estudos em equipes multiprofissionais para se ter uma compreensão exata em relação aos fatores maternos que conduzem ao processo de desmame precoce;

- a/o enfermeira/o descubra com a comunidade, outras plantas a que são atribuídas efeito galactógeno e pesquise;

- a/o enfermeira/o utilize os recursos tecnológicos apropriados/práticas caseiras, comprovadamente eficazes, como instrumentos de orientação nos programas de incentivo ao aleitamento materno.

\section{SUMMARY}

The objective of this research is an attempt to show the potentiality of aniseed as a lactation process stimulant..

Women in the last three months of pregnancy were selected at the public pre-natal clinic in Aquiraz, Ceará to answer questionaries; the purpose was to select a sample of women with a common history of milk.

From the results obtained in the research intend to recommend the use of aniseed/appropriate techonology as one more strategy in improving the health, of both mother and child. 
Nóbrega S. e Colaboradora - A Erva-Doce e seu Efeito Galactógeno (Um Estudo Experimental). Rev. Bras. Enf.; RS.36: 163 - 177, 1983.

\section{BIBLIOGRAFIA}

1. A CRIANÇA alimentada ao seio "Leva Vantagem em Tudo". (Extraído do Manual de Fomento para Lactância Materna - Chile. Adaptação: INAMPS - HPEAM). 11p. (mimeo).

2. BENSON, Ralph C. Manual de Obstetrícia \& Ginecologia. 5. ed. Rio de Janeiro, KOOGAN, 1976. p. 194-99.

3. FERREIRA, Emília de Jesus et alii. Época e causas do Desmame no município de Niterói. Rev. Alimentação \& Nutrição. Rio de Janeiro, (6): 52-57, out./dez. 1981.

4. FRANCENELY, Neiva \& NOBREGA, Silvia. Ervas, Uma Terapêutica no Campo da Enfermagem. Fortaleza, 1981. 74j. (mimeo). Enviado para publicação na Rev. Bras. de Enfermagem.

5. HARNACK, Gustav Adolf Von, et alii. Manual de Pediatria. 4. ed. São Paulo, EPU, 1977. p. 76-83.

6. MAMEDE, Marli Villela et alii. Importância da Amamentação no Relacionamento Saudável Mãe e Filho. Rev. Bras. de Enfermagem. Rio de Janeiro, 32 (3): 229-302, jul./ago./set. 1979.

7. MORLEY, David. Amamentação e Dificuldades na Alimentação Artificial. In: Pediatria no Mundo em Desenvolvimento. São Paulo, Paulinas, 1980. p. 83-99.

8. NÓBREGA, Sîvia \& FRANCENELY, Neiva. Práticas Caseiras no Cuidado a Saúde/Tecnologia Apropriada. Fortaleza, 1981, 65p. (mimeo). Enviado para publicação na Rev. Bras. Enfermagem.

9. OMS/UNICEF. Alimentação de Lactentes e Crianças na Primeira Infância. Genebra, 1980, 99p.

10. OMS/UNICEF. Alimentação de Lactentes e Crianças na Primeira Infância. A Boa Iniciação Nutricional. Genebra, 1980, 40p.

11. ROSA, Miriam Susete de, et alii. Como Proteger a Criança de 0 a 24 meses Contra a Infecção. Rev. Bras. de Enfermagem. Brasília, 32:271-295, jul./ago./set. 1979.

12. RESUMOdas Características relevantes dos resultados da pesquisa de aleitamento materno. UNICEF, 1981. 27p. (mimeo).

13. SERVIÇOS Educacionais/Laboratório Abbott. Como Amamentar o seu bebê. (Folder)

14. UNICEF. Incidência da Amamentação e seu Impacto na Saúde da Criança. Brasîia, 1978. 9p.

15. MALDONADO, Maria Tereza; NAHONN. Jean Claude; DICKPTEIN, Júlio. Nós Estamos Grávidos. Block Editores, 1979. 12p.

\section{ANEXO I}

№ 1-INSTRUMENTO PARA SELEÇÃO DA AMOSTRA

\section{I - IDENTIFICAÇÃO:}

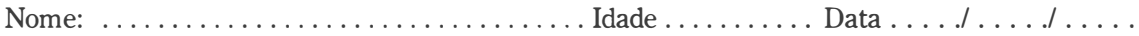

Endereço: N. $\ldots$

№ de filhos

D.P.P.

Data da próxima consulta

Assinatura

II - DADOS RELATIVOS À GESTAÇÃO ANTERIOR:

01 . Como a senhora se sentiu na gravidez anterior?

Feliz ( ) Triste ( ) Indiferente ( )

Outros (escrever) .

02. Como foi seu último parto?

Cesåria ( ) Normal ( ) A ferro ( )

03. Amamentou seu último filho?

Sim ( ) Por quanto tempo?

$$
\text { Por que? }
$$

Não ( ) Por que?

04. A criança durante este tempo só mamou?

Sim ( )

Não ( ) Quando foi introduzida a outra alimentação? ............. Dias de nascido.

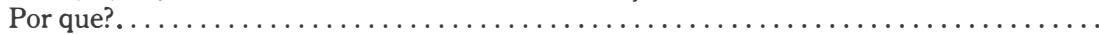

05. O que o seu companheiro acha da amamentação?

Deve amamentar ( )

Não deve ( )

Indiferente ( ) 
III - DADOS RELATIVOS À GESTAÇÃO ATUAL:

01 . A senhora tem ou teve alguma doença nesta gravidez?

Sim ( ) Qual?.

Não ( )

02. Vem tomando ou tem tomado algum remédio?

Sim ( ) Qual?

Não ( )

03. Como a senhora está se sentindo nesta gravidez?

Feliz ( ) Triste ( ) Indiferente ( )

Outros (escrever)

04. Como a senhora vê a mulher que dá de mamar?

Acha bonito ( ) Acha feio ( ) Indiferente ( )

\section{PERGUNTE E OBSERVE}

01. Tem bico no peito?

Sim ( ) Não ( )

02. Pretende dar de mamar ao filho que vai nascer?

Sim ( ) Não ( )

Presença de bico no peito

Sim ( ) Não ( )

Aceitação da amamentação por parte da mãe (escrever) . .

ANEXO II

INSTRUMENTO № 1

PROCEDIMENTOS PARA TREINAMENTO* DO APLICADOR:

1. - Instruções quanto à aplicação do formulário:

- apresentar o formulário

- demonstrar a técnica de aplicação

- simular a aplicação do formulário

2. - Aplicação do formulário pela parteira por ocasião do pré natal a gestantes no último trimestre da gravidez, no período de 5 dias.

3. - Verificação das autoras junto ao aplicador no terceiro dia de treinamento quanto às dificuldades sentidas referente ao formulário e sua aplicação.

4. - Observação pelas autoras da aplicação do formulário pelo aplicador no quarto dia.

5. - Avaliação pelas autoras junto ao aplicador da fase de treinamento e formulário utilizado.

\section{ANEXO III}

\section{PROCEDIMENTOS PARA CONFIRMAÇÃO NA PARTICIPAÇÃO NO GRUPO NA PESQUISA}

Entrevista ** com cada gestante selecionada, abordando os seguintes temas:

- estudos anteriormente realizados na área relativo a utilização de ervas no cuidado caseiro da saúde;

- informar sobre os objetivos da pesquisa e a que se propõe;

- explicar o papel a ser desempenhado pela mesma na pesquisa;

- confirmar sua participação.

* Concomitantemente ao treinamento do aplicador o Instrumento foi testado.

** Foi utilizada a entrevista para evitar a adesão por indução do grupo e não da própria pessoa. 
Nóbrega S. e Colaboradora - A Erva-Doce e seu Efeito Galactógeno (Um Estudo Experimental). Rev. Bras. Enf.; RS.36: 163 - 177, 1983.

\section{ANEXO IV \\ PREPARAÇÃO DO CHÁ DE ERVA-DOCE}

- Três (03) colheres de chá de erva-doce, para 1 litro de água.

MODO DE FAZER:

- coloque em um recipiente 1 litro d'água e leve ao fogo, deixe ferver por algum tempo *

- coloque em outro recipiente 3 colheres de chá contendo sementes de erva-doce e aguarde;

- quando a água estiver fervida, despeje no recipiente que contém as sementes do erva-doce;

- deixe esfriar, coe e aguarde em um recipiente limpo (garrafa, etc.).

\section{UTENSÍLIOS NECESSÁRIOS:}

- 1 colher de chá

- 2 papeiros ou panelas

- 1 garrafa com capacidade de 1 litro

ANEXO V

PROCEDIMENTOS NA EXPERIMENTAÇÃO DA VARIÁVEL

1. - Preparação da amostra para a amamentação. Orientação quanto a:

- limpeza das mamas antes e após cada mamada, com água morna, com pano limpo ou algodão;

- adoção de uma posição confortável, mãe e bebê;

- pressão do peito com um dedo a fim de mantê-lo afastado do nariz do bebê, para que o mesmo respire livremente;

- uso de ambas as mamas, toda vez que dá de mamar;

- número de vezes para amamentação: sempre que a criança desejar;

- colocar a criança para arrotar após cada mamada;

- utilizar colherinha para dar água ou chá ao bebê.

2. - Preparação da amostra para utilização do chá. Orientação quanto a:

- utilização do chá obedecendo à posologia recomendada, desde as primeiras horas do puerpério, na própria maternidade;

- observação da parteira preparando o chá.

3. - O ingrediente necessário para a preparação do chá no próprio domícilio, foi entregue à gestante selecionada no 9 . mês de gestação.

\section{ANEXO VI}

\section{N. 2 - INSTRUMENTO PARA COLETA DOS RESULTADOS NA MATERNIDADE:}

Nome da mãe:

I CARACTERIZADO DO PARTO:

Data

01. Como foi seu último parto?

Cesário ( ) Normal ( ) A ferro ( )

02. Como a senhora se sentiu neste parto?

Experiência boa ( ) Experiência ruim ( )

Outros (escrever)

03. A criança foi levada ao peito antes da secção do coto umbilical?

Sim ( ) Não ( ) Por que?..

* Tempo máximo para fervura, 15 minutos. 
Nóbrega S. e Colaboradora - A Erva-Doce e seu Efeito Galactógeno (Um Estudo Experimental). Rev. Bras. Enf.; RS.36: 163 - 177, 1983.

04. A senhora tem tomado o chá?

Quanto? menos de 1 copo ( ) 1 copo ( )

Quantas vezes/dia?.

Nome da criança: .

Coleta: Data

N. .

Assinatura

II) DADOS RELATIVOS À CRIANÇA:

01. Peso Estatura

02. Estado geral:

Bom ( ) regular ( )

03. A criança está sendo amamentada?

Sim ( ) Não ( ) Por que?

\section{INSTRUMENTO PARA COLETA DOS RESULTADOS NO DOMICÍLIO DA PUERPERA: \\ COLETA/DATA}

No.

Assinatura:

01. A senhora tem tomado o chá?

Quanto? Menos de 1 copo ( ) 1 copo ( )

Quantas vezes/dia?

02. A criança está só mamando?

Sim ( ) Não ( ) Por que?

03. Como a criança fica depois de cada mamada?

Dorme ( ) Chora ( )

Outros (especificar)

04. Tomando como base a amamentação do puerpério anterior, a quantidade de leite:

Aumentou ( ) Não aumentou ( ) Diminuiu ( )

DEPOIMENTOS DA PUÉRPERA:

\section{ANEXO VII}

TABELA 1 - Sentimentos do grupo amostral com relação ao estado gestacional. Aquiraz - CE, 1982.

\begin{tabular}{lcccc}
\hline \multirow{2}{*}{$\begin{array}{l}\text { Estado } \\
\text { gestacional }\end{array}$} & \multicolumn{3}{c}{ Sentimentos } & \\
\cline { 2 - 4 } & Feliz & Triste & Indiferente & Total \\
\hline Anterior & $\mathrm{O} 4$ & - & 01 & 05 \\
Atual & 01 & 02 & 02 & 05 \\
\hline
\end{tabular}

Fonte: Formulário aplicado pelas parteiras. 
Nóbrega S. e Colaboradora - A Erva-Doce e seu Efeito Galactógeno (Um Estudo Experimental). Rev. Bras. Enf.; RS.36: 163 - 177, 1983.

TABELA 2 - Grupo amostral segundo o tipo de parto nas gestações anterior e atual. Aquiraz, CE, 1982.

\begin{tabular}{lcccc}
\hline \hline \multirow{2}{*}{ Gestação } & \multicolumn{3}{c}{ Tipos de Parto } & \\
\cline { 2 - 5 } & Normal & Cesária & A Ferro* & Total \\
\hline Anterior & 05 & - & - & 05 \\
Atual & 05 & - & - & 05 \\
\hline
\end{tabular}

Fonte: Formulário aplicado pelas parteiras e autoras.

Obs.: * Fórceps.

TABELA 3 - Experiências do grupo amostral segundo época de realização do parto. Aquiraz - CE, 1982.

\begin{tabular}{|c|c|c|c|}
\hline \multirow{2}{*}{ Parto } & \multicolumn{2}{|c|}{ Experiência } & \multirow{2}{*}{ Total } \\
\hline & Boa & Ruim & \\
\hline Anterior & 04 & 01 & 05 \\
\hline Atual & 03 & 02 & 05 \\
\hline
\end{tabular}

Fonte: Formulário aplicado pelas parteiras e autoras.

TABELA 4 - Experiência de amamentação do último filho e a expectativa de amamentar o filho da gestação atual. Aquiraz, CE, 1982.

\begin{tabular}{lccllll}
\hline \hline \multirow{2}{*}{ Amamentação } & \multicolumn{2}{c}{ Experiência } & & \multicolumn{2}{c}{ Expectativa } \\
\cline { 2 - 3 } \cline { 5 - 6 } & Sim & & Não & & Sim & Não \\
\hline Do último filho & 05 & - & & - & - \\
Deseja amamentar & - & - & & 05 & - \\
\hline
\end{tabular}

Fonte: Formulário aplicado pelas parteiras.

TABELA 5 - Incentivo do companheiro com relação a amamentação no ciclo grávido-puerperal anterior e atual. Aquiraz, CE, 1982.

\begin{tabular}{lcc}
\hline \hline Incentivo do companheiro & \multicolumn{2}{c}{ Ciclo grávido-puerperal } \\
\cline { 2 - 3 } na amamentação & Anteriòr & Atual \\
\hline Deve & 03 & 03 \\
Não deve & - & - \\
Indiferente & 02 & 02 \\
\hline Total & 05 & 05 \\
\hline
\end{tabular}

Fonte: Formulário aplicado pelas parteiras. 
Nóbrega S. e Colaboradora - A Erva-Doce e seu Efeito Galactógeno (Um Estudo Experimental). Rev. Bras. Enf.; RS.36: 163 - 177, 1983.

TABELA 6 - Enfermidades identificadas no grupo amostral na gestação atual. Aquiraz-CE, 1982.

\begin{tabular}{lc}
\hline \hline Enfermidades* & Grupo Amostral \\
identificadas & $02^{* *}$ \\
\hline Sim & 03 \\
Não & 05 \\
\hline TOTAL & \\
\hline
\end{tabular}

Fonte: Formulário aplicado pelas parteiras.

Obs.: * - Sinal ou sintoma de qualquer natureza.

** - Coceira, fraqueza.

TABELA 7 - Terapêutica medicamentosa* utilizada pelo grupo amostral durante a gestação atual. Aquiraz-CE, 1982.

\begin{tabular}{lc}
\hline \hline Terapêutica & Grupo Amostral \\
medicamentosa * & $02^{* *}$ \\
\hline Sim & 03 \\
Não & 05 \\
\hline TOTAL &
\end{tabular}

Fonte: Formulário aplicado pelas parteiras.

Obs.: * - Fármacos industrializados ou caseiros.

** - Polivitaminas, pomadas antibióticas.

TABELA 8 - Como vê o grupo amostral o ato de amamentar por outra mulher. Aquiraz-CE, 1982.

\begin{tabular}{lc}
\hline \hline Como vê & Grupo Amostral \\
\hline Bonito & 05 \\
Feio & - \\
Indiferente & 05 \\
\hline TOTAL & \\
\hline
\end{tabular}

Fonte: Formulário aplicado pelas parteiras.

TABELA 9 - Proeminência de mamilo no grupo amostral. Aquiraz, CE-1982.

\begin{tabular}{lc}
\hline \hline Proeminência & Grupo Amostral \\
de mamilo & 05 \\
\hline Sim & - \\
Não & 05 \\
\hline TOTAL &
\end{tabular}

Fonte: Formulário aplicado pelas parteiras.

Obs.: * - Bico do Peito 
Nóbrega S. e Colaboradora - A Erva-Doce e seu Efeito Galactógeno (Um Estudo Experimental).

Rev. Bras. Enf.; RS.36: 163 - 177, 1983.

TABELA 10 - Amamentação da criança pelo grupo amostral antes da secção do coto umbilical. Aquiraz - CE, 1982.

\begin{tabular}{cc}
\hline \hline $\begin{array}{c}\text { Amamentação/grupo amostral } \\
\text { antes da secção do coto }\end{array}$ & No. de crianças \\
\hline Sim & 03 \\
Não & 02 \\
\hline TOTAL & 05 \\
\hline
\end{tabular}

Fonte: Formulário aplicado pelas autoras

TABELA 11 - Posologia utilizada pelo grupo amostral quando da utilização do chá. Aquiraz, CE, 1982.

\begin{tabular}{cc}
\hline \hline Posologia* & Grupo Amostral \\
\hline 1 copo & 05 \\
Menos de 1 copo & - \\
\hline
\end{tabular}

TOTAL

05

Fonte: Formulário aplicado pelas autoras.

Obs.: * Posologia adotada na pesquisa - 1 copo/4 vezes ao dia.

\section{METODOLOGIA DA ASSISTÊNCIA DE ENFERMAGEM - UMA NOVA ESTRATÉGIA DE EDUCAÇÃO EM SAÚDE}

* Sônia Maria Passos da Silva Pinto

* Miriam Santos Paiva

$\mathrm{ReBEn}_{11} /() 6$

Silva PintoS. M. P. e Colaboradora - Metodologia da Assistência - Uma Nova Estratégia de Educação em Saúde. Rev. Bras. Enf.; RS, 36: 177-182, 1983

\section{RESUMO}

A partir da análise de programas de Assistência de Enfermagem à comunidade, já desenvolvidos, constatou-se a presença de ações puramente assistencialistas que não determinam modificações no "Status quo" e assim não produzem mudanças nos problemas apresentados pelo grupo assistido. Na

* Professores Assistentes do Departamento de Enfermagem Comunitária da Escola de Enfermagem da Universidade Federal da Bahia. 